\title{
Ion Pair Extraction in Preparative Organic Chemistry. XI. Extraction of Sulfonic Acids as Ion Pairs with Amines
}

\author{
ARNE BRÄNDSTRÖM and GERT STRANDLUND
}

\author{
AB Hässle, Fack, S-431 20 Mölndal 1, Sweden
}

Sulfonic acids can usually be extracted from an aqueous solution to an organic layer as ion pairs with amines. The degree of extraction is readily predicted in a semiquantitative manner using simple rules and a limited number of measurements with different sulfonic acids, amines and solvents.

Sulfonic acids and their salts are a class of organic compounds with important applications in all branches of chemistry. They have often been difficult to isolate and to purify, however, due to their unfavourable solubility properties. The literature is filled with cumbersome processes for their isolation and separation. Brändström, ${ }^{2-3}$ however, has reported that the anions of sulfonic acids are usually readily extracted as ion pairs with cations from amines. We have now examined more carefully this method of obtaining pure salts of sulfonic acids.

The extraction process

The process is based on the reactions given in Scheme 1.

$$
\begin{aligned}
& \mathrm{B}_{\mathrm{s}}+\mathrm{H}^{+}{ }_{\mathrm{w}} \rightleftharpoons\left(\mathrm{HB}^{+}\right)_{\mathrm{w}} \\
& \left(\mathrm{RSO}_{3}^{-}\right)_{\mathrm{w}}+\left(\mathrm{HB}^{+}\right)_{\mathrm{w}} \rightleftharpoons\left(\mathrm{RSO}_{3}^{-} \mathrm{HB}^{+}\right)_{\mathrm{s}} \\
& \left(\mathrm{RSO}_{3}^{-} \mathrm{HB}^{+}\right)_{\mathrm{s}}+\left(\mathrm{OH}^{-}\right)_{\mathrm{w}} \rightleftharpoons\left(\mathrm{RSO}_{3}^{-}\right)_{\mathrm{w}}+\mathrm{B}_{\mathrm{s}}
\end{aligned}
$$

\section{Scheme 1.}

Here $B_{s}$ functions as a liquid ion exchanger and is recovered at the end of the process.

In this sequence of reactions the anions $\mathrm{RSO}_{3}^{-}$are separated from other anions that are not extracted under the same conditions. The extraction equilibrium is governed by the choice of the amine $B$, the solvent and the concentrations used. As in other cases in which ion pair extraction is involved, a quantitative prediction of the degree of extraction should be based on a knowledge of the extraction constant. ${ }^{3}$

From the theory for hydrophobicity and extraction 4,5 it can be expected that extraction constants can be predicted by eqn. (1) ${ }^{5}$

$e_{\mathrm{HBX}}=F_{\mathrm{HB}^{+}} F_{\mathrm{X}}-F_{\mathrm{S}} \quad \mathrm{M}^{-1}$

where the $F$ factors are characteristic for the component indicated. In order to calculate extraction constants, we have thus to construct a list of $F_{\mathrm{HB}^{+}}, F_{\mathrm{X}^{-}}$and $F_{\mathrm{s}}$ values valid for a variety of acids, amines and solvents. The construction of this list is highly facilitated by the fact that $F_{\mathrm{HB}^{+}}$and $F_{\mathrm{X}^{-}}$are readily calculated directly from simple structure elements in a similar way as the distribution constants for uncharged molecules are calculated from the hydrophobic fragmental constants $\pi$ or $f{ }^{6}$

Limitations of the method due to sidereactions

There are some factors which restrict the choice of the base B. The most important one is that $B$ must be present in the proper protolytic form at the different steps of the process. B should therefore be strong enough to be present almost entirely in the $\left(\mathrm{HB}^{+}\right)_{\mathrm{w}}$ form at a low $\mathrm{pH}(0-1)$ and weak enough to be present almost entirely in the $\mathrm{B}_{\mathrm{s}}$ form at $\mathrm{pH}$ $8-9$. This restricts the choice of $B$ to anilines, pyridine bases, morpholino derivatives, triallyl amines and bases of similar strengths.

Acta Chem. Scand. B 32 (1978) No. 7 
Side reactions of the type adduct formation and dimerisation within the organic layer or ion pair formation within the aqueous layer should also be avoided in the standard situation. At present these effects are difficult to predict in a quantitative manner due to a lack of basic knowledge of the constants for the reactions involved. In the standard procedure the amine should thus not contain $\mathrm{NH}$ or $\mathrm{OH}$ groups ${ }^{5}$ and it should not contain extended aromatic ring systems (vide infra).

In order to avoid difficulties due tọ differences in salting out effects, ${ }^{5}$ the ionic composition of the aqueous layer should be as constant as possible. In this investigation this problem has been solved by using $1 \mathrm{M} \mathrm{H}_{2} \mathrm{SO}_{4}$ as the aqueous layer. This is also a medium that is natural in many preparative situations.

A combination of a very hydrophilic ion with a hydrophobic counter ion will, in some cases, give a three-layer system. In many cases this can be avoided by using another, usually better, extracting solvent or by diluting the aqueous layer.

When these rules are followed, extraction equilibria are obtained, which in most cases are readily predictable and which make selective extractions possible.

A rapid method for the deter. mination of the extraction constant

Extraction constants can be accurately determined by a variety of methods. ${ }^{7}$ For the present purpose where the demand for accuracy is fairly low and the number of constants to be determined is rather high, a rapid method was needed. Such a method was found in the titration of the aminium ion of the ion pair in the organic layer by standard alkali in a twolayer system. Most of the $e$ values in this paper were calculated from determinations at one or two concentrations with this method. If sidereactions occur, these values are in error. By control experiments performed at different dilutions we have tried to detect side-reactions, such as dimerisation of the ion pair within the organic layer or ion pair formation within the aqueous layer. We have not been able to detect such reactions, except in case where we had good reasons to predict that hey should occur. e.g. dimerisation in the extraction with $N$ methylaniline or ion pair formation within the aqueous layer in extractions with quinoline. These side-reactions are discussed under the next heading. It should, however, be admitted that dimerisation constants $<2 \mathrm{M}^{-1}$ are difficult to detect. To ignore such a small dimerisation might give rise to an error in the extraction constant by a factor $<2.5$. This figure should be compared with the ratio of extraction constants between compounds fully extracted (>99\% extraction) and those not extracted ( $<1 \%$ extraction). This ratio is $>10^{4}$. For practical purposes, however, the extraction constants obtained by this method are as useful as the correct constants since they include at least some of the effects of the dimerisation.

\section{Dimerisation of the ion pair within the organic layer}

This type of side reaction has been observed in many extractions and is very pronounced when formation of strong hydrogen bonds between two ion pairs can be expected. The practical consequences of the dimerisation for preparative extractions have been treated elsewhere. ${ }^{8}$ Dimerisation can be discovered if the extraction is performed at different concentrations. When dimerisation occurs, the degree of extraction will increase more rapidly with an increase in concentration than when dimerisation does not occur. This effect is probably most easily seen if the ratio between the highest and the lowest degree of extraction is compared with the values calculated for different values of the dimerisation constant (see Table 1). From Table 1 we can see that the degree of dimerisation is low when the extraction is performed with a tertiary amine such as $N, N$-dimethylaniline.

In the extraction with a secondary amine such as $N$-methylaniline we can expect a high degree of dimerisation. We have in this case observed a very rapid increase in the degree of extraction when the volume of the aqueous layer was decreased. When dimerisation occurs, the total concentration $C_{\mathrm{s}}$ in the organic layer can be expressed by eqn. (2),

$C_{\mathrm{s}}=\left[\mathrm{HB}^{+}\right]_{\mathrm{w}}\left[\mathrm{X}^{-}\right]_{\mathrm{w}} e_{\mathrm{HBX}}+$

$2 K_{2}\left(e_{\mathrm{HBX}}\right)^{2}\left[\mathrm{HB}^{+}\right]^{2}{ }_{\mathrm{w}}\left[\mathrm{X}^{-}\right]^{2}{ }_{\mathrm{w}}$

Acta Chem. Scand. B 32 (1978) No. 7 
Table 1. Control experiment to investigate if dimerisation occurs in the extraction of 2-hydroxy5-methylbenzenesulfonic acid with $N, N$-dimethylaniline and dichloromethane.

\begin{tabular}{lllllll}
\hline & & Found & \multicolumn{3}{l}{ Calculated $\mathrm{X}_{\mathrm{s}}^{-} / \mathrm{mmol}$} \\
\cline { 5 - 7 }$s / \mathrm{cm}^{3}$ & $w / \mathrm{cm}^{3}$ & $\mathrm{X}_{\mathrm{s}}^{-} / \mathrm{mmol}$ & $a$ & $b$ & $c$ & $d$ \\
\hline 17.60 & 17.11 & 8.4 & 8.53 & 8.68 & 8.71 & 8.76 \\
17.01 & 32.70 & 6.5 & 6.44 & 6.60 & 6.62 & 6.69 \\
16.52 & 48.20 & 4.9 & 4.75 & 4.78 & 4.77 & 4.80 \\
16.05 & 63.66 & 3.4 & 3.55 & 3.42 & 3.37 & 3.34 \\
15.80 & 78.91 & 2.6 & 2.70 & 2.50 & 2.41 & 2.34 \\
Ratio between highest and & 3.23 & 3.15 & 3.47 & 3.61 & 3.75 \\
Rewest extraction values & & & & & \\
\hline
\end{tabular}

a Calculated on the basis: $e_{\mathrm{HBX}}=8.4 \quad \mathrm{M}^{-1} ; K_{2}=0 \mathrm{M}^{-1}$.

${ }^{b}$ Calbulated on the basis: $e_{\mathrm{HBX}}=6 \quad \mathrm{M}^{-1} ; K_{2}=1 \mathrm{M}^{-1}$.

c Calculated on the basis: $e_{\mathrm{HBX}}=5 \quad \mathrm{M}^{-1} ; K_{2}=2 \mathrm{M}^{-1}$.

${ }^{d}$ Calculated on the basis: $e_{\mathrm{HBX}}=3.75 \mathrm{M}^{-1} ; K_{2}=5 \mathrm{M}^{-1}$.

from which $e_{\mathrm{HBX}}$ and $K_{2}$ may be calculated. In the present case the dimerisation is so extensive that the concentration of the ion pair is very low compared to that of the dimer. This results in a value for $e_{\mathrm{HBX}}$ which is too small to be accurately calculated, but the product $K_{2}\left(e_{\mathrm{HBX}}\right)^{2}$ is found to be $11.5 \mathrm{M}^{-3}$. This is in agreement with the values $e_{\mathrm{HBX}}=$ $0.025 \mathrm{M}^{-1}$ and $K_{2}=1.84 \times 10^{4} \mathrm{M}^{-1}$ which are of the magnitude expected ${ }^{5}$ for this extraction (Table 2).

Ion pair formation in the aqueous layer

This type of side-reaction is rarely observed but has been suggested in the extraction of ions with condensed aromatic ring systems and

Table 2. The extraction of 4-methylbenzenesulfonic acid with $N$-methylaniline. Formation of ion pair dimers.

\begin{tabular}{|c|c|c|c|c|}
\hline \multirow[t]{2}{*}{$s / \mathrm{cm}^{3}$} & \multirow[t]{2}{*}{$w / \mathrm{cm}^{3}$} & \multicolumn{2}{|c|}{$\mathrm{X}^{-} / \mathrm{mmol}$} & \multirow{2}{*}{$e^{\mathrm{x}}{ }_{\mathrm{HBX}} / \mathrm{M}^{-1}$} \\
\hline & & Found & Calc. $^{a}$ & \\
\hline 12.29 & 10.57 & 8.2 & 8.35 & 3.51 \\
\hline 11.56 & 21.30 & 5.6 & 5.51 & 3.47 \\
\hline 10.89 & 31.97 & 3.2 & 3.18 & 2.63 \\
\hline 10.45 & 42.41 & 1.6 & 1.72 & 1.78 \\
\hline 10.25 & 52.61 & 0.9 & 0.94 & 1.39 \\
\hline
\end{tabular}

${ }^{a}$ Calculated on the basis of $e_{\mathrm{HBX}}=0.025 \mathrm{M}^{-1}$, $K_{2}=1.84 \times 10^{4} \quad \mathrm{M}^{-1}$.

Acta Chem. Scand. B 32 (1978) No. 7 a mathematical model for this has been presented. ${ }^{7}$ The practical consequences of this type of side-reaction are that the degree of extraction is not increased as rapidly as in an uncomplicated extraction when the concentration in the aqueous layer is increased.

We have observed this phenomenon in connection with extractions with quinoline. In order to test if ion pair formation within the aqueous layer might be responsible for the effect, extractions were made with two different solvents. Merely a change of extracting solvent should not change the ion pair formation constant $k^{\mathrm{w}}{ }_{\mathrm{HBX}}$ since this reaction occurs entirely within the aqueous layer.

The constants $e_{\mathrm{HBX}}$ and $k^{\mathrm{w}}{ }_{\mathrm{HBX}}$ involved were calculated by means of a computer program based on the mathematical model for this sidereaction. ${ }^{7}$ From Tables 3 and 4 we can see that the same $k^{\mathrm{w}}$ HBX value can be used in both cases. The resulting extraction constants are of the magnitude expected and their ratio is the correct one for this change of solvent.

In the extraction of 2-naphthalenesulfonic acid with $N, N$-dimethylaniline and dichloromethane at different dilutions of the aqueous and the organic layers, we obtained results which indicated ion pair formation within the aqueous layer, as well as dimerisation of the ion pair within the organic layer. Such a system, which is governed by at least 3 constants, is much too complicated, however, to be investigated by the present method. 
Table 3. The extraction of 2-hydroxy-5-methylbenzenesulfonic acid with quinoline and dichloromethane. Ion pair formation within the aqueous layer.

\begin{tabular}{|c|c|c|c|c|c|c|}
\hline \multirow[b]{2}{*}{$w / \mathrm{cm}^{3}$} & \multirow[b]{2}{*}{$s / \mathrm{cm}^{3}$} & \multirow{2}{*}{$\begin{array}{l}\text { Found } \\
\mathrm{HBX} / \mathrm{mmol}\end{array}$} & \multicolumn{4}{|c|}{ Calculated $^{a}$ quantities of $/ \mathrm{mmol}$} \\
\hline & & & $\overline{\mathrm{HBX}_{\mathrm{s}}}$ & $\mathrm{HBX}_{\mathrm{w}}$ & $\mathbf{X}_{\mathbf{w}}^{-}$ & $\mathrm{HB}_{\mathbf{w}}+$ \\
\hline 16.7 & 47.2 & 6.9 & 6.89 & 2.94 & 0.20 & 10.2 \\
\hline 21.8 & 46.9 & 6.1 & 6.20 & 3.50 & 0.30 & 10.3 \\
\hline 31.9 & 46.5 & 5.2 & 5.17 & 4.30 & 0.53 & 10.5 \\
\hline 47.1 & 46.3 & 4.1 & 4.08 & 5.04 & 0.89 & 10.9 \\
\hline 62.2 & 46.0 & 3.3 & 3.32 & 5.45 & 1.22 & 11.2 \\
\hline 92.3 & 45.8 & 2.4 & 2.37 & 5.80 & 1.83 & 11.8 \\
\hline
\end{tabular}

${ }^{a}$ These values are obtained from the computer calculations with $e_{\mathrm{HBX}}=20.6 \mathrm{M}^{-1}$ and $k^{\mathrm{w}} \mathrm{HBX}=25 \mathrm{M}^{-1}$.

Table 4. The extraction of 2-hydroxy-5-methylbenzenesulfonic acid with quinoline and 1,1,2,2tetrachloroethane. Ion pair formation within the aqueous layer.

\begin{tabular}{|c|c|c|c|c|c|c|}
\hline \multirow[b]{2}{*}{$w / \mathrm{cm}^{3}$} & \multirow[b]{2}{*}{$s / \mathrm{cm}^{3}$} & \multirow{2}{*}{$\begin{array}{l}\text { Found } \\
\mathrm{HBX} / \mathrm{mmol}\end{array}$} & \multicolumn{4}{|c|}{ Calculated ${ }^{a}$ quantities of $/ \mathrm{mmol}$} \\
\hline & & & $\overline{\mathrm{HBX}_{\mathrm{s}}}$ & $\mathrm{HBX}_{\mathrm{w}}$ & $\mathrm{X}_{\mathrm{w}}^{-}$ & $\mathrm{HB}_{\mathrm{w}}+$ \\
\hline 21.4 & 32.8 & 8.8 & 8.42 & 1.46 & 0.13 & 10.13 \\
\hline 31.6 & 32.5 & 7.9 & 7.75 & 2.00 & 0.25 & 10.25 \\
\hline 46.7 & 32.2 & 7.0 & 6.88 & 2.65 & 0.47 & 10.47 \\
\hline 61.8 & 31.9 & 6.0 & 6.12 & 3.15 & 0.73 & 10.73 \\
\hline 92.0 & 31.6 & 4.9 & 4.93 & 3.82 & 1.25 & 11.25 \\
\hline 122.1 & 31.3 & 4.0 & 4.05 & 4.20 & 1.75 & 11.75 \\
\hline 152.2 & 31.0 & 3.2 & 3.38 & 4.41 & 2.21 & 12.21 \\
\hline 182.2 & 30.9 & 2.8 & 2.88 & 4.52 & 2.60 & 12.60 \\
\hline
\end{tabular}

${ }^{a}$ These values are obtained from the computer calculations with $e_{\mathrm{HBX}}=94 \mathrm{M}^{-1}$ and $k^{\mathrm{w}}{ }_{\mathrm{HBX}}=25 \mathrm{M}^{-1}$.

If both the cation and the anion have extended aromatic ring systems a formation might be expected of strong ion pairs of the sandwich type within the aqueous layer. This will reduce the total wetted area compared to that of the free ions and thus reduce the hydrophobicity.9 This is in agreement with the fact that no extraction of 2-naphthalenesulfonic acid could be observed in a standard experiment with quinoline and dichloromethane although the hydrophobicity of both ions would indicate extraction to a very high degree. This demonstrates that the rules given in this paper must be handled with care as soon as ion pair formation within the aqueous layer can be expected and it also indicates a way to obtain very selective extractions.
Calculation and accuracy of the $F$ factors

Rekker ${ }^{6}$ has tried to calculate hydrophobic fragmental constants, $f$, for charged molecules. His approach, as well as that of Leo et al., however, ends up in confusion. The reason for this is that they do not distinguish between extraction constants with the dimension $\mathbf{M}^{-1}$ and partition coefficients which are dimensionless. A partition coefficient can never be obtained for an ion, since the partition is dependent on the structure and the concentration of the counter ion. This problem is circumvented by the use of eqn. (1) which contains extraction constants instead of partition coefficient. We have good indications ${ }^{5}$

Acta Chem. Scand. B 32 (1978) No. 7 
that for a given solvent $e_{\mathrm{HBX}}$ values can be divided into $F_{\mathrm{HB}^{+}}$and $F_{\mathrm{X}^{-}}$values with the aid of eqn. (1). Almost nothing is known about the $F_{\mathrm{s}}$ factor, however. We have many semiquantitative indications that $F_{\mathrm{s}}$ is roughly the same for a given solvent even if the type of ion pair is varied within wide limits. A more quantitative indication for this can be found from Table 5 where the $\log F_{\mathrm{s}}$ values calculated from measurements of distributions of aminium salts of 4-methylbenzenesulfonic acid are compared with those obtained from tetrabutylammonium bromide. ${ }^{5}$ We can see that the

Table 5. The solvent factor $\log F_{\mathrm{s}}$ for different solvents in the extraction of the ion pairs; 4methylbenzenesulfonic acid: triallylamine (I) and tetrabutylammonium bromide (II).

Solvent

Ion pair I Ion pair II

\begin{tabular}{|c|c|c|}
\hline $\mathrm{CH}_{2} \mathrm{Cl}_{2}$ & 0.0 & 0.0 \\
\hline $\mathrm{CHCl}_{3}$ & $0.0^{a}$ & 0.1 \\
\hline $\mathrm{CCl}_{4}$ & $<-3.0$ & $<-2.5$ \\
\hline $\mathrm{CH}_{3} \mathrm{CHCl}_{2}$ & -1.6 & -1.8 \\
\hline $\mathrm{CH}_{2} \mathrm{ClCH}_{2} \mathrm{Cl}$ & -0.5 & -0.8 \\
\hline $\mathrm{CH}_{2} \mathrm{ClCHCl}_{2}$ & -0.3 & -0.6 \\
\hline $\mathrm{CHCl}_{2} \mathrm{CHCl}_{2}$ & 0.4 & 0.6 \\
\hline $\mathrm{CHCl}_{2} \mathrm{CCl}_{3}$ & $<-3.0$ & $<-2.5$ \\
\hline $\mathrm{CH}_{3} \mathrm{CHClCH}_{2} \mathrm{Cl}$ & -2.2 & -1.8 \\
\hline $\mathrm{CH}_{2} \mathrm{ClCH}_{2} \mathrm{CH}_{2} \mathrm{Cl}$ & $-1.9^{b}$ & -1.1 \\
\hline $\mathrm{CH}_{2} \mathrm{ClCHClCH}_{2} \mathrm{Cl}$ & -0.7 & -0.8 \\
\hline $\mathrm{Cl}\left(\mathrm{CH}_{2}\right)_{4} \mathrm{Cl}$ & -1.9 & -2.0 \\
\hline $\mathrm{CH}_{2}=\mathrm{CCl}_{2}$ & $<-3.0$ & $<-2.5$ \\
\hline cis $\mathrm{CHCl}=\mathrm{CHCl}$ & 0.0 & 0.0 \\
\hline $\operatorname{trans} \mathrm{CHCl}=\mathrm{CHCl}$ & $<-3.0$ & $<-2.5$ \\
\hline $\mathrm{CHCl}=\mathrm{CCl}_{2}$ & $<-3.0$ & -2.2 \\
\hline $\mathrm{CCl}_{2}=\mathrm{CCl}_{2}$ & $<-3.0$ & - \\
\hline $\mathrm{CH}_{2}=\mathrm{CClCH}_{2} \mathrm{Cl}$ & -1.3 & - \\
\hline $\mathrm{C}_{6} \mathrm{H}_{5} \mathrm{Cl}$ & -2.1 & $<-2.5$ \\
\hline$o \cdot \mathrm{C}_{6} \mathrm{H}_{4} \mathrm{Cl}$ & -2.2 & $<-2.5$ \\
\hline $\mathrm{CH}_{3} \mathrm{NO}_{2}$ & $0.9^{c}$ & 0.7 \\
\hline $\mathrm{C}_{3} \mathrm{H}_{7} \mathrm{NO}_{2}$ & - & -0.6 \\
\hline $\mathrm{C}_{6} \mathrm{H}_{5} \mathrm{NO}_{2}$ & $-1.1^{a}$ & - \\
\hline $\mathrm{C}_{3} \mathrm{H}_{7} \mathrm{CN}$ & $-1.1^{a}$ & -0.4 \\
\hline $\mathrm{C}_{6} \mathrm{H}_{5} \mathrm{CN}$ & -0.5 & - \\
\hline $\mathrm{CNCH}_{2} \mathrm{CN}$ & $1.9^{c}$ & - \\
\hline $\mathrm{ClCH}_{2} \mathrm{CN}$ & $1.8^{c}$ & 2.7 \\
\hline $\mathrm{ClCH}_{2} \mathrm{CH}_{2} \mathrm{CN}$ & $1.3^{c}$ & 1.4 \\
\hline $\mathrm{CH}_{3}\left(\mathrm{CH}_{2}\right)_{3} \mathrm{OH}$ & - & 0.3 \\
\hline $\mathrm{C}_{2} \mathrm{H}_{5} \mathrm{COCH}_{3}$ & - & -0.4 \\
\hline $\mathrm{CH}_{3} \mathrm{COOC}_{2} \mathrm{H}_{5}$ & $-1.9^{b}$ & -2.2 \\
\hline $\mathrm{ClCH}_{2} \mathrm{COOC}_{2} \mathrm{H}_{5}$ & $-1.3^{a}$ & -1.4 \\
\hline $\mathrm{CNCH}_{2} \mathrm{COOCH}_{3}$ & $0.1^{a}$ & 0.2 \\
\hline$\left(\mathrm{ClCH}_{2} \mathrm{CH}_{2}\right)_{2} \mathrm{O}$ & $-1.7^{b}$ & -1.1 \\
\hline
\end{tabular}

${ }^{a} N, N$-Dimethylaniline, ${ }^{b} N, N$-diethylaniline, c 2-methylpyridine used instead of triallylamine. agreement between these two sets of values is usually good, but that a few exceptions occur. They are, however, very small compared to the total range of $\log F_{\mathrm{s}}$ values, which is more than 5 log units. We have thus a good in. dication that even $F_{\mathrm{s}}$ values can be handled in eqn. (1).

For that purpose, the zero point for the log $F$ values has to be defined. We have done this by the arbitrary choice of $\log F_{\mathrm{s}}=0$ for dichloromethane and $\log F_{\mathrm{HB}^{+}}=0$ for $N, N$. dimethylaniline. In this way the scale for $\log$ $F_{\mathrm{X}^{-}}$will be defined by $\log \boldsymbol{F}_{\mathrm{X}^{-}}=\log e_{\mathrm{HBX}}$ for the extraction of $\mathrm{X}^{-}$with $N, N$-dimethylaniline and dichloromethane.

This enabled a calculation of $\log F$ values from experimental $e_{\mathrm{HBX}}$ values in the following way: The $\log F$ values to be determined and the experimental $\log e_{\mathrm{HBX}}$ values were introduced in eqn. (1) written in the logarithmic form

$$
\log e_{\mathbf{H B X}}=\log F_{\mathbf{X}^{-}}+\log F_{\mathbf{H B}^{+}}+\log F_{\mathrm{s}}
$$

From 94 values of $\log e$ (Table 9) obtained from 16 acids listed in Table 6, 5 amines (Table 7), and 4 solvents (Table 8), we obtained 94 equations from which $16+5+4-2=23$ $\log F$ values had to be calculated. This was readily done by a computor using the method of least squares, minimizing the errors in $\log e_{\mathrm{HBX}}$. The $\log F$ values thus obtained are given in Tables 6-8. They can be used to calculate $\log e_{\mathrm{HBX}}$ values for other combinations of acids, amines and solvents. For solvents other than those found in Table 8 the $F_{\mathrm{s}}$ values given in Table 5 might be used for approximative estimations of extraction constants, hopefully correct within $\pm 1 \log$ unit.

It is still more interesting to see, however, if the results can be used for more general predictions. Since partition coefficients can be divided into a few additive hydrophobic fragmental constants, ${ }^{\circ}$ it seems logical that the same should be valid for the $\log F_{\mathrm{X}^{-}}$and $\log F_{\mathrm{HB}^{+}}$factors. It was found that 6 fragments $f$ (Table 10) could replace the $16 \log F_{\mathrm{X}^{-}}$and the $5 \log F_{\mathrm{HB}^{+}}$values in the calculations above. The fragment $f$ (steric) was introduced to account for the higher extraction constant of 2 hydroxybenzenesulfonates substituted in the 3 or 6 position compared to those with the same substituent in another position. The fragment

Acta Chem. Scand. B 32 (1978) No. 7 
Table 6. $\log F_{\mathrm{X}}$-values for some sulfonic acids $\left(\mathrm{R}-\mathrm{C}_{6} \mathrm{H}_{4}-\mathrm{SO}_{3}{ }^{-}\right)$.

\begin{tabular}{|c|c|c|c|c|c|}
\hline \multirow[t]{2}{*}{ Code } & \multirow[t]{2}{*}{$\mathbf{R}$} & \multicolumn{3}{|l|}{ Found } & \multirow{2}{*}{$\frac{\text { Calc. }^{a}}{\log F_{\mathrm{X}}}$} \\
\hline & & $\overline{\log F_{\mathrm{X}^{-}}}$ & $\delta \log F_{\mathrm{X}^{-}}$ & $n$ & \\
\hline 1 & $\mathrm{H}$ & -0.68 & 0.19 & 8 & -0.60 \\
\hline 2 & $4-\mathrm{CH}_{3}$ & -0.02 & 0.24 & 8 & 0.02 \\
\hline 3 & 2,4-di- $-\mathrm{CH}_{3}$ & 0.65 & 0.13 & 4 & 0.64 \\
\hline 4 & $4-\mathrm{CH}\left(\mathrm{CH}_{3}\right)_{2}$ & 1.64 & 0.29 & 6 & 1.26 \\
\hline $\mathbf{5}$ & $2-\mathrm{OH}$ & 0.25 & 0.11 & 11 & 0.22 \\
\hline 6 & $2-\mathrm{OH}-3-\mathrm{CH}_{3}$ & 1.24 & 0.27 & 13 & 1.27 \\
\hline 7 & $2-\mathrm{OH}-4-\mathrm{CH}_{3}$ & 0.97 & 0.10 & 7 & 0.84 \\
\hline 8 & $2-\mathrm{OH}-5-\mathrm{CH}_{3}$ & 0.92 & 0.17 & 17 & 0.84 \\
\hline 9 & $2 \cdot \mathrm{OH} \cdot 6 \cdot \mathrm{CH}_{3}$ & 1.19 & 0.16 & 2 & 1.27 \\
\hline 10 & $2-\mathrm{OH}-3,5-\mathrm{diCH}_{3}$ & 1.98 & 0.15 & 3 & 1.89 \\
\hline 11 & $2-\mathrm{OH} \cdot 3-\mathrm{CH}\left(\mathrm{CH}_{3}\right)_{2}$ & 2.61 & 0.49 & 2 & 2.51 \\
\hline 12 & $2-\mathrm{OH}-5-\mathrm{CH}\left(\mathrm{CH}_{3}\right)_{2}$ & 2.25 & 0.20 & 4 & 2.08 \\
\hline 13 & $2-\mathrm{OH}-5-\mathrm{C}\left(\mathrm{CH}_{3}\right)_{3}$ & 2.57 & 0.39 & 4 & 2.70 \\
\hline 14 & $2-\mathrm{OH}-3-\mathrm{CH}_{3}-5-\mathrm{C}\left(\mathrm{CH}_{3}\right)_{3}$ & 3.82 & 0.39 & 2 & 3.75 \\
\hline 15 & $2-\mathrm{OH}-3,5-\mathrm{diCH}\left(\mathrm{CH}_{8}\right)_{2}$ & 5.22 & - & 1 & 4.37 \\
\hline 16 & $2-\mathrm{OH} \cdot 3,5-\mathrm{diC}\left(\mathrm{CH}_{3}\right)_{3}$ & 5.66 & 0.35 & 2 & 5.61 \\
\hline
\end{tabular}

${ }^{a}$ Calculated from the $f$ values in Table 10.

Table 7. $\log \boldsymbol{F}_{\mathrm{HB}^{+}}$values for some amines.

\begin{tabular}{llllrl}
\hline Code & Amine & Found & & & Calc. \\
\cline { 4 - 5 } & & $\log F_{\mathrm{HB}^{+}}$ & $\delta \log F$ & $n$ & $\frac{1}{\log F_{\mathbf{X}}}$ \\
\hline a & $N, N$-Dimethylaniline & 0.00 & 0.23 & 38 & 0 \\
b & $N, N$-Diethylaniline & 1.13 & 0.23 & 25 & 1.24 \\
c & Pyridine & -2.41 & 0.32 & 6 & -2.21 \\
d & 2-Methylpyridine & -1.71 & 0.31 & 15 & -1.59 \\
e & 2,6-Dimethylpyridine & -1.00 & 0.09 & 8 & -0.97 \\
\hline
\end{tabular}

${ }^{a}$ Calculated from the $f$ values in Table 10.

Table 8. $\log \boldsymbol{F}_{\mathrm{s}}$ values for some solvents.

\begin{tabular}{|c|c|c|c|c|}
\hline \multirow[t]{2}{*}{ Code } & \multirow[t]{2}{*}{ Solvent } & \multicolumn{3}{|l|}{ Found } \\
\hline & & $\log F_{\mathrm{s}}$ & $\delta \log F_{\mathrm{s}}$ & $n$ \\
\hline $\mathbf{A}$ & 1,2-Dichloroethane & -0.59 & 0.34 & 27 \\
\hline $\mathbf{B}$ & Dichloromethane & 0.00 & 0.18 & 31 \\
\hline $\mathbf{C}$ & Chloroform & -0.08 & 0.31 & 16 \\
\hline $\mathrm{D}$ & $1,1,2,2$-Tetrachloroethan $\theta$ & 0.51 & 0.11 & 20 \\
\hline
\end{tabular}

$f\left(\mathrm{CH}_{2}\right)$ is the most fundamental of them all, since every alkyl group can be constructed by successive insertions of $\mathrm{CH}_{2}$ groups. Preliminary calculations indicate that $f\left(\mathrm{CH}_{2}\right)$ is 0.62 which is identical with the value found in other in- vestigations. $^{5}$ In the final least squares calculation, which was performed by a stepwise multiple regression computer program, we therefore assigned the value of 0.62 to $f\left(\mathrm{CH}_{2}\right)$. We can see the good agreement between the 
Table 9. $\log e_{\mathrm{HBX}}$ values for the combinations of acids, amines and solvents indicated by the code given in Tables 6-8.

\begin{tabular}{|c|c|c|c|c|c|c|c|}
\hline Code & Found & Calc. $^{a}$ & Diff. & Code & Found & Calc. $^{a}$ & Diff. \\
\hline Aal & -1.26 & -1.19 & -0.07 & $\mathrm{Bb8}$ & 2.07 & 2.08 & -0.01 \\
\hline Abl & -0.47 & 0.05 & -0.52 & Bd8 & -0.80 & -0.67 & -0.13 \\
\hline Aa2 & -0.90 & -0.57 & -0.33 & $\mathrm{Be8}$ & -0.12 & -0.05 & -0.07 \\
\hline $\mathrm{Ab2}$ & 0.28 & $\mathbf{0 . 6 7}$ & -0.39 & Ba9 & 1.26 & 1.27 & -0.01 \\
\hline $\mathrm{Aa} 3$ & 0.14 & 0.05 & 0.09 & Bal0 & 1.90 & 1.89 & 0.01 \\
\hline Ab3 & 1.15 & 1.29 & -0.14 & Bdlo & 0.21 & 0.31 & -0.10 \\
\hline Aa4 & 1.33 & 0.67 & 0.66 & Bal2 & 2.13 & 2.08 & 0.05 \\
\hline $\mathrm{Ab4}$ & 2.00 & 1.91 & 0.09 & $\mathrm{Bd12}$ & 0.81 & 0.49 & 0.32 \\
\hline Aa5 & -0.51 & -0.37 & -0.14 & Bal3 & 2.40 & 2.70 & -0.30 \\
\hline Ab5 & 0.99 & 0.87 & 0.12 & Bdl3 & 1.36 & 1.11 & 0.25 \\
\hline Aa6 6 & 0.99 & 0.68 & 0.31 & $\mathrm{Bd} 14$ & 2.42 & 2.16 & 0.26 \\
\hline Aa7 & 0.34 & 0.25 & 0.09 & Cal & -0.87 & -0.68 & -0.19 \\
\hline Aa8 & 0.51 & 0.25 & 0.26 & $\mathrm{Cbl}$ & 0.68 & 0.56 & 0.12 \\
\hline Ab8 & 1.77 & 1.49 & 0.28 & Ca 2 & -0.01 & -0.06 & 0.05 \\
\hline Ad8 & -1.15 & -1.34 & 0.19 & $\mathrm{Cb2}$ & 1.44 & 1.18 & 0.26 \\
\hline $\mathrm{A} \theta 8$ & -0.61 & -0.72 & 0.11 & $\mathrm{Ca4}$ & 1.77 & 1.18 & 0.59 \\
\hline Aalo & 1.50 & 1.30 & 0.20 & Ca5 & 0.03 & 0.14 & -0.11 \\
\hline Aall & 2.31 & 1.92 & 0.39 & $\mathrm{Ca} 6$ & 1.37 & 1.19 & 0.18 \\
\hline Abl1 & 2.85 & 3.15 & -0.30 & Cc6 & -1.67 & -1.02 & -0.65 \\
\hline Aal2 & 1.72 & 1.49 & 0.23 & $\mathrm{Cd} 6$ & -0.87 & -0.40 & -0.47 \\
\hline Abl2 & 2.60 & 2.73 & -0.13 & $\mathrm{Ce} 6$ & 0.24 & 0.22 & 0.02 \\
\hline Aal3 & 2.10 & 2.11 & -0.01 & $\mathrm{Ca} 7$ & 0.80 & 0.76 & 0.04 \\
\hline Abl3 & 2.69 & 3.35 & -0.66 & $\mathrm{Cb} 7$ & 2.23 & 2.00 & 0.23 \\
\hline Aal4 & 2.87 & 3.16 & -0.29 & $\mathrm{Ca} 8$ & 0.80 & 0.76 & 0.04 \\
\hline Ad15 & 2.99 & 2.19 & -0.80 & $\mathrm{Cb8}$ & 2.19 & 2.00 & 0.19 \\
\hline Acl 6 & 3.06 & 2.81 & 0.25 & $\mathrm{Cd} 8$ & -1.21 & -0.83 & -0.38 \\
\hline Ad16 & 3.18 & 3.43 & -0.25 & $\mathrm{Ce} 8$ & -0.35 & -0.21 & -0.14 \\
\hline Bal & -0.78 & -0.60 & -0.18 & Dal & -0.16 & -0.09 & -0.07 \\
\hline $\mathrm{Bbl}$ & 0.49 & 0.64 & -0.15 & Dbl & 1.20 & 1.15 & 0.05 \\
\hline $\mathrm{Ba2}$ & -0.23 & 0.02 & -0.25 & Da2 & 0.49 & 0.53 & -0.04 \\
\hline Bb2 & 1.04 & 1.26 & -0.22 & $\mathrm{Db2}$ & 1.94 & 1.77 & 0.17 \\
\hline Ba3 & 0.70 & 0.64 & 0.06 & Da4 & 2.04 & 1.77 & 0.27 \\
\hline Bb3 & 1.73 & 1.88 & -0.15 & Da5 & 0.64 & 0.73 & -0.09 \\
\hline Ba4 & 1.70 & 1.26 & 0.44 & Dc5 & -1.57 & -1.48 & -0.09 \\
\hline Bb4 & 2.43 & 2.50 & -0.07 & Dd5 & -0.89 & -0.86 & -0.03 \\
\hline Ba5 & 0.05 & 0.22 & -0.17 & De5 & -0.24 & -0.24 & 0.00 \\
\hline Bb5 & 1.45 & 1.46 & -0.01 & Da6 & 1.85 & 1.78 & 0.07 \\
\hline Bd5 & -1.36 & -1.54 & 0.18 & Dc6 & -0.49 & -0.43 & -0.06 \\
\hline Be5 & -0.81 & -0.92 & 0.11 & Dd6 & 0.26 & 0.19 & 0.07 \\
\hline Ba6 & 1.37 & 1.27 & 0.10 & Da7 & 1.29 & 1.35 & 0.06 \\
\hline Bb6 & 2.45 & 2.51 & -0.06 & Db7 & 2.48 & 2.59 & -0.11 \\
\hline Bc6 & -1.20 & -0.84 & -0.36 & Da8 & 1.39 & 1.35 & 0.04 \\
\hline Bd6 & -0.40 & -0.22 & -0.18 & Db8 & 2.50 & 2.59 & -0.09 \\
\hline Be6 & 0.38 & 0.40 & -0.02 & Dc8 & -0.83 & -0.86 & 0.03 \\
\hline $\mathrm{Ba} 7$ & 0.89 & 0.84 & 0.05 & Dd8 & -0.27 & -0.24 & -0.03 \\
\hline Bb7 & 2.11 & 2.08 & 0.03 & $\mathrm{De8}$ & 0.50 & 0.38 & 0.12 \\
\hline $\mathrm{Ba8}$ & 0.92 & 0.84 & 0.08 & Da9 & 1.54 & 1.78 & -0.24 \\
\hline
\end{tabular}

$a$ These values were obtained using the $f$ values in Table 10 and the $\log F_{\mathrm{s}}$ values in Table 8 .

experimental $\log e_{\mathrm{HBx}}$ values and those calculated with the help of the $4 \log F_{\mathrm{s}}$ and 6 $f$-values (Table 9). We can also see that the log $F$ values obtained from the experiments (found in Tables 6 and 7) agree with those calculated Acta Chem. Seand. B 32 (1978) No. 7 from the fragments. The value $\delta \log F$ given there is the standard deviation in the $\log F$ value calculated on the assumption that the total error in the measurements of $\log e_{\mathrm{HBX}}$ is to be found in that $\log F$ value. 
Table 10. Primary set of hydrophobic fragmental constants, $f$ for calculations of $\log e$ values for different pairs of sulfonic acids and amines.

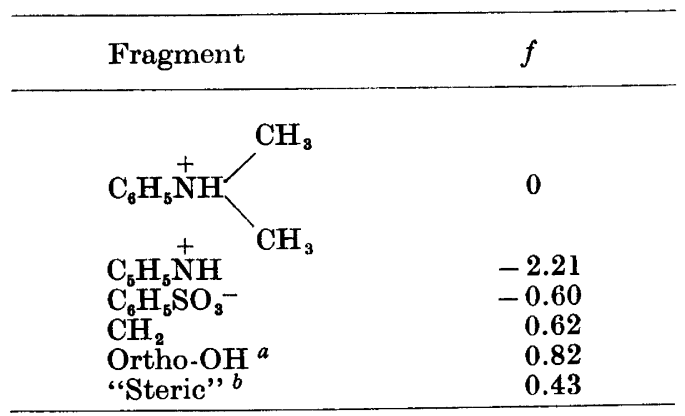

a Formally this is a $\pi$ value and not a fragment since hydrogen is replaced by an OH-group. $b$ This factor accounts for the increased hy. drophobicity caused by the buttressing effect of alkyl groups in 1, 2, 3-tri-substituted hydroxybenzenesulfonic acids.

The fragments given in Table 10 enable us to predict the $\log F_{\mathrm{x}^{-}}$values of most benzenesulfonic acids containing alkyl or 2-hydroxy groups up to a point where the hydrophobicity of the anion makes meaningful measurements impossible.

From the limited number of experimental data available at present, it is not possible to give accurate $f$ values for more fragments than those given in Table 10. We have, however, some possibilities for predicting the extractability of sulfonic acids with structures not covered by these fragments.

The distributive parameter $\pi$ for a substituent is widely used ${ }^{10,11}$ to account for the increase in the logarithm of the distribution coefficient ( $\log K_{\mathrm{D}}$ ) for an uncharged molecule when an aromatic hydrogen is replaced by that substituent. From the theory of hydrophobicity, ${ }^{4,5}$ it can further be assumed that there is a good correlation between the variation of $\log k_{\mathrm{D}}$ with the substituents in an uncharged molecule and the variation of $\log e$ with the same substituents in an ion pair. The best correlation can be expected when the substituent is in. troduced in a meta or para position and when the substituent does not seriously change the resonance of the molecule. The only systematic comparison of that kind at present available is that on halogenated and nitrated phenols ${ }^{18}$
Table 11. The $\pi$ value for some substituents on aromatic sulfonic acids.

\begin{tabular}{lcl}
\hline Substituent & $\pi$ & $n$ \\
\hline$m-\mathrm{NO}_{2}$ & 0.94 & 8 \\
$\mathrm{OCH}_{3}$ & 0.18 & 2 \\
$p-\mathrm{OH}$ & -2.1 & 1 \\
$\mathrm{Cl}$ & 1.15 & 4 \\
$\mathrm{Br}$ & $1.35^{a}$ & \\
$\mathrm{I}$ & $\mathbf{1 . 6 5}^{a}$ & \\
\hline
\end{tabular}

${ }^{a}$ Estimated from Ref. 12.

which demonstrated the points mentioned above. The $\pi$-value might thus be used to make a rough estimation of the effect of a substituent on the $\log e$ value. Extensive lists of $\pi$ values are available, ${ }^{10,11}$ but it should be remembered that these values are valid for the system octanol-water. The values for the system chloroform-water are often $20 \%$ higher. $^{6}$ It should also be remembered that the $\pi$ values should be used with caution when the substituent is in the ortho position and especially if the substituent is a strongly interactive group such as $\mathrm{NH}_{2}, \mathrm{OH}$ or $\mathrm{NO}_{2}$.

Table 11 contains $\pi$ values of a few important substituents for the system dichloromethanewater. Some of them have been obtained from distribution experiments with the sulfonic acids in Table 12 and some are estimated with the help of other distribution data. ${ }^{12}$

Table 12. The value of the $F$-factor for some sulfonic acids and amines not given in Tables $6-9$.

$\log F$

\section{4-Methoxy-3-}

methylbenzenesulfonic acid

2-Methoxy-5-tert-

butylbenzenesulfonic acid

4-Methyl-3-

nitrobenzenesulfonic acid

3-Nitrobenzenesulfonic acid

0.34

3,5-Dimethylcyclohexyl

hydrogen sulfate

Cyclohexanesulfamic acid

$-0.04$

$N$-Ethylcyclohexanesulfamic acid $\quad 1.94$

Camphor-10-sulfonic acid $\quad-0.07$

Triallylamine

0.85

$N$-Benzylmorpholine 
It should also be possible to calculate $\log F_{\mathrm{X}^{-}}$ values for sulfonic acids with the $\mathrm{SO}_{3} \mathrm{H}$ group not present on an aromatic ring using the principles given above if the $\log \boldsymbol{F}_{\mathbf{X}}$ values are known for a few reference compounds. These are also found in Table 12, together with the $\log F_{\mathrm{HB}^{+}}$values of a few important cations.

\section{Illustration}

To illustrate how the calculated parameters can be used to predict the extraction behaviour of a sulfonic acid, an example will be given of a solution to a problem of a common type.

Suppose that we have a solution of 4-methoxy-3-methylbenzenesulfonic acid in sulfuric acid and wish to extract at least $90 \%$ of the acid with an equal portion of 1,1,2,2-tetrachloroethane containing $N$-ethyl- $N$-methylaniline. Is this possible and how much of the aniline is needed?

For the calculation of the extraction constant we need the $\log F$ values. $\log F_{\mathrm{s}}=0.51$ is directly obtained from Table $8 . \log F_{\mathrm{HB}^{+}}=$ 0.62 is obtained by the addition of the $f$ values for the fragments $\mathrm{C}_{5} \mathrm{H}_{6}-\mathrm{NH}\left(\mathrm{CH}_{3}\right)_{2}$ and $\mathrm{CH}_{2}$ (Table 10). $\log F_{\mathrm{X}^{-}}=0.20$ is obtained by the addition of the $f$ values for the fragments $\mathrm{C}_{5} \mathrm{H}_{6} \mathrm{SO}_{3}{ }^{-}$and $\mathrm{CH}_{2}$ (Table 10 ) and the $\pi$ value for $\mathrm{CH}_{3} \mathrm{O}$ (Table 11). (The found value for $F_{X^{-}}$is 0.32 (Table 12).) Introducting these $\log$ $F$ values in eqn. (3) gives $\log e_{\mathrm{HBX}}=1.33$.

With equal phase volumes and $90 \%$ extraction wanted, we can write $[\mathrm{HBX}]_{\mathrm{s}} /\left[\mathrm{X}^{-}\right]_{\mathrm{w}}=9$. If this and the $\log e_{\mathrm{HBX}}$ value is introduced in eqn. (4) for the extraction equilibrium $\log [\mathrm{HBX}]_{\mathrm{S}} /\left[\mathrm{X}^{-}\right]_{\mathrm{w}}=\log e_{\mathrm{HBX}}+\log \left[\mathrm{HB}^{+}\right]_{\mathrm{w}} \quad$ (4) we obtain $\left[\mathrm{HB}^{+}\right]_{\mathrm{w}}=0.42$. We have thus to use a quantity of $B$ at least sufficient to form the ion pair extracted and to give this concentration in the aqueous layer.

\section{LIST OF SYMBOLS}

$\begin{array}{ll}\mathrm{B} & =\text { Amine } \\ \mathrm{HB}^{+} & =\text {Aminium ion } \\ \mathrm{X}^{-} & =\text {Anion of a sulfonic acid } \\ e_{\mathrm{HBX}} & =\text { The stoichiometric extrac- } \\ & \text { tion constant } \\ e^{\mathrm{x}} \mathrm{HBX} & =\text { The conditional extraction } \\ & \text { constant } \\ w & =\text { Volume of the aqueous } \\ & \text { layer }\end{array}$

$\begin{array}{lrl}s & =\text { Volume of the solvents } \\ F_{\mathrm{HB}^{+}}, F_{\mathrm{X}^{-}} \text {and } F_{\mathrm{s}}= & \text { Hydrophobic factor for the } \\ & \text { cation, anion and solvent } \\ & \text { used } \\ = & \text { Total concentration of } \mathrm{X}^{-} \\ & \text {in the solvent layer } \\ = & \text { Hydrophobic fragmental } \\ & \left.\text { constant (log } F=\sum_{\mathrm{i}} f_{\mathrm{i}}\right) \\ \mathrm{C} & =\text { Ion pair dimerization con- } \\ & \text { stant } \\ = & \text { The stoichiometric ion pair } \\ & \text { formation constant in } \\ & \text { water } \\ = & \text { Distribution parameter for } \\ & \text { aromatic substituent } \\ k_{2}^{\mathrm{w}}{ }_{\mathrm{HBX}} & \text { Distribution coefficient of } \\ & \text { a uncharged molecule. In } \\ & \text { Refs. 4, } 6,10 \text { and } 11 \text { the } \\ \pi & \text { symbol } \mathrm{P} \text { is used for this } \\ & \text { coefficient }\end{array}$

\section{EXPERIMENTAL}

The solvents, the amines, the chlorosulfonic acid and the following sulfonic acids were commercial products: 4-methylbenzenesulfonic acid, 3-nitrobenzenesulfonic acid, camphor-10-sulfonic acid and sodium cyclohexane sulfamate. NMR spectra were measured on Varian T-60 and CFT-20 instruments. Computer calculations were made on a Digital PDP 8 computer.

The identity of the products was established by $\mathrm{H}$ and ${ }^{13} \mathrm{C}$ NMR analysis. The absence of $\mathrm{SO}_{4}{ }^{2-}$ and $\mathrm{Cl}^{-}$ions in the products was estab. lished by precipitation tests with $\mathrm{BaCl}_{2}$ and $\mathrm{AgNO}_{3}$.

$A$ general procedure for the preparation of ophenolsulfonic acids and their potassium salts. One equivalent of a phenol was treated with 1.1 equivalent of chlorosulfonic acid in dichloromethane at $-20^{\circ} \mathrm{C}$. The mixture was allowed to stand for $2-3 \mathrm{~h}$ until it had reached room temperature and was then poured into ice water. The amount of water was chosen so that the solution became $1-1.5 \mathrm{M}$ with respect to the sulfonic acid.

A suitable amine (1.1-2 equivalents) was then added. The selection of the amine was made according to the principles presented, usually $N, N$-diethylaniline for hydrophilic acids and $N, N$-dimethylaniline or 2-methylpyridine for more hydrophobic acids. If necessary the $\mathrm{pH}$ was adjusted to less than 1 with sulfuric acid. The water layer was extracted with dichloromethane and, if the extraction was insufficient, a better solvent selected from Table 5 was used for the extraction. Some water was added to the combined organic layers

Acta Chem. Scand. B 32 (1978) No. 7 
containing the $o$-phenolsulfonic acid and the mixture was stirred and titrated with $1 \mathbf{M}$ potassium hydroxide to $\mathrm{pH}$ 7-7.5.

The solvent was separated and the water layer washed twice with dichloromethane to remove the amine. The water was then evaporated and the potassium salt recrystallized from a suitable solvent.

Potassium 3,5-dimethylcyclohexyl sulfate. One mol of 3,5-dimethylcyclohexanol (Fluka) was treated with $1.1 \mathrm{~mol}$ of chlorosulfonic acid in ether at $-10^{\circ}$. The work-up procedure was analogous to that of phenolsulfonic acids using $N, N$-dimethylaniline and dichloromethane, yield $71 \%$.

Potassium N-ethyl-N-cyclohexyl sulfamate. The compound was prepared according to the procedure in Ref. 13 , yield $62 \%$.

$A$ general procedure for determination of the extraction constant. $10 \mathrm{mmol}$ of a sulfonic acid or its potassium salt was dissolved in $15.0 \mathrm{ml}$ or $1 \mathrm{M}$ sulfuric acid. $20 \mathrm{mmol}$ of the amine was added and the mixture was extracted with $15.0 \mathrm{ml}$ of the solvent. If the estimated degree of extraction was lower than $20 \%$ or higher than $80 \%$, an appropriate multiple of the solvent or sulfuric acid volume was added to place the degree of extraction within the limits mentioned.

After extraction, the organic layer was carefully separated, mixed with an equal amount of water and titrated under stirring with $1 \mathbf{M}$ potassium hydroxide. The conditional extraction constant $e^{\mathrm{x}} \mathrm{HBX}$ was calculated using the formula:

$e_{\mathrm{HBX}}^{\mathrm{X}}=\frac{\mathrm{X}}{(10-X)(10-X)} \times \frac{w^{2}}{s} \mathrm{M}^{-1}$

where $X=\mathrm{mmol}$ of $X^{-}$found by titration.

The transport of matter from one layer to the other, resulted in a slight change in the volumes $s$ and $w$. Control experiments showed that, within the experimental errors, the change in volume expressed in ml was identical to the weight of the transported matter in g. Corrections of $s$ and $w$ were therefore made in accordance with this.

Acknowledgement. This work was supported by the Swedish Natural Science Research Council.

\section{REFERENCES}

1. Houben-Weyl, Methoden der Organischen Chemie, Georg Thieme, Stuttgart 1955, Vol. 4/2, p. 514 and Vol. 9, pp. 444-448.

2. Brändström, A. Kem. Tidskr. (1970, 5-6) 1 .

3. Brändström, A. Preparative Ion Pair Extraction Apotekarsocieteten, Stockholm 1974.
4. Leo, A., Hansch, C. and Elkins, D. Chem. Rev. 71 (1971) 525.

5. Brändström, A. Adv. Phys. Org. Chem. 15 (1977) 267.

6. Rekker, R. The Hydrophobic Fragmental Constant, Elsevier, Amsterdam 1977.

7. Schill, G. In Marinsky, J. A. and Markus, Y., Eds., Ion Exchange and Solvent Extraction, Dekker, New York 1974, Vol. 6, p. 1.

8. Gustavii, K., Brändström, A. and Allansson, S. Acta Chem. Scand. 25 (1971) 77.

9. Yalkowsky, S. H. and Valvani, S. C. J. Med. Chem. 19 (1976) 727.

10. Hansch, C., Leo, A., Unger, S. H., Kim, K. H., Nikaitani, D. and Lien, E. J. J. Med. Chem. 16 (1973) 1207.

11. Norrington, F. E., Hyde, R. M., William, S. G. and Wootton, R. J. Med. Chem. 18 (1975) 604.

12. Johansson, P. A. Acta Pharm. Suec. 14 (1977) 345.

13. Houben-Weyl, Methoden der Organischen Chemie, Thieme, Stuttgart 1958, Vol. 11/2, p. 658 .

Received April 13, 1978. 